\title{
Online education: creating conditions for students to succeed
}

\author{
Olga Kovbasyuk ${ }^{1, *}$, and Angelina Dolgaya \\ ${ }^{1}$ I. Kant Baltic Federal University, Kaliningrad, Russia \\ ${ }^{2}$ Kaliningrad State Technical University, Kaliningrad, Russia
}

\begin{abstract}
This paper focuses on a key success factor in higher education, which is its management, related to creating conditions for successful education. The notion "successful education" is complicated and it has not been analyzed conceptionally. We argue that successful education is the one which provides students with experience to succeed in life. The models of successful online education should aim at supporting students' experience rather than at providing admission to the technology itself. Management in higher education, in this case will be built on organization students' experience which leads to successful education. X culture model has proved to serve this purpose.
\end{abstract}

\section{Introduction}

Online education has become almost "a norm" in education due to the pandemic of 20202021. We apply the term "online education" to designate formal education which occurs with the help of computer technologies regardless of the location. It provides many benefits to students, such as alternative forms of interaction with educational resources, numerous means of data transfer, a lot of options for communication.

Though it may seem that online education is everywhere now, it still remains a new element in the system of higher education and main educational models are still being created. We hold that the models of successful online education should aim at supporting students' experience rather than at providing admission to the technology itself. Management in higher education, in this case, will be built on organization students' experience which leads to successful education.

The notion successful education is complicated and it has not been analyzed conceptionally. We argue that successful education is the one which provides students with experience to succeed in life.

"All educational practices can be seen as successful when the authors can plan the precise desired effect of their efforts, and the point is merely to plot a course toward it. The model of education badly needed at the beginning of the twenty first century, however is the one of a common journey, shared exploration of unknown shores; and the most valuable result of this journey is not the maps and trophies, but rather the mature traveler" Leontiev.

\footnotetext{
* Corresponding author: OVKovbasiuk@kantiana.ru
} 
We argue that it is experience which makes a learner mature and online education is an excellent way to provide multiple experiences, such as participation in a global dialogue. A global space of interaction in which there are multiple voices and no certainties has become the reality of life, but it is the job of education to make this a road to success for students.

The philosophy of experiential learning, which posits that experience provides the foundation for learning, is attributed to the work of John Dewey (1938). An implicit assumption of this philosophy is that direct contact in a learning environment will evoke reactions that become part of a symbolic, internalized learning experience. An instructor focuses on learners' attention and structure the learning environment, while it is the learner's experience that creates the learning content.

Experiential Learning has become an important area of scholarship in business education since the entrepreneurial model of behavior focuses mostly on the practically applied skills and competencies, which could be acquired and developed by learners in experiential studies. No matter how highly skillful teachers are, they can hardly be able to transfer the knowledge of "how to do things" to their learners' heads (Baartman and Ruijs, 2011).

Current conceptualization of experiential learning builds on Dewey's pragmatism, and focuses on education, Levin's social psychology and group dynamics, and Piaget's model of learning and development. Whereas experiential education focuses on the process by which teachers involve learners, experiential learning focuses on how individuals learn from their experiences, even without a teacher. In the experiential studies described here, learners and teachers are to transform their roles and practices in such a way that the teaching culture is replaced by the learning one, and learners take much more responsibility for their own experiential education tracks. Experiential learning is less about instructional design, than about the personally-interpreted experience of each learner. Thus, in experiential learning, educational programs become less teacher focused and more student-centered (Savicki, 2008).

This article aims at revealing a key success factor in managing online education, which is creating conditions for experiential learning. $\mathrm{X}$ culture is viewed as an online experiential education which facilitates the transformation of students' personal mastery. Authors explain how these experiences enhance the personal and professional development of graduate students. The article tackles the question of what facilitates the transformation of learners' attitudes toward learning and personal mastery. The authors will illustrate the process of such facilitation within an entrepreneurial graduate program in the Institute of Economics, Management and Tourism, I. Kant Baltic Federal University.

\section{Materials and methods}

A number of studies have provided evidence for the effectiveness of experiential learning in business education, transformative education and meaning -centered education (Alon, 2003; Cheney, 2001; Ng, Paul \& Mukhopad- hyay, 2005; Fenwick, 2003; Kovbasyuk and Blessinger, 2013; Brookfield, 1995; Cranton, 1994; Merirow and Taylor, 2009). Digital Age education has been reviewed as a way to enhance students' experience in the $21^{\text {st }}$ century (Beetham, Sharpe, 2013, Coates, 2006, Laurillard, 2013, Zepke, 2010)

The global online project X culture which was launched in 2010 in the USA, has proved to become experiential in its nature as participation in a globally virtual team based project offers a "prototype" of the real-world globally interconnected workplace. Thus, it offers a chance to experience the challenges of cross-cultural collaboration and as such, to engage in experiential learning relevant to international collaboration. As defined by Kolb (1984), experiential learning is a "holistic integrative perspective on learning that combines experience, cognition, and behavior" (Kolb, 1984). 
The number of participants in this global online project has been growing every year. Today, around 5000 students from more than 150 universities in over 70 countries on six continents participate in this unique global project.

The Institute of Economics, Management and Tourism, I. Kant Baltic Federal University joined this project in 2013 and students have been participating in it ever since. What they do as participants is they apply to participate and take a readiness test to be admitted, then they are enrolled in global virtual teams on a project for about two months. While the participants are students, the international collaboration challenges they encounter are similar to those experienced by employees of multinational companies, and so facilitate the acquisition of cross-cultural management skills.

Participants communicate in English with each other using free online collaboration tools, such as email, Skype, Google+, Facebook, Dropbox, and Doodle - the same ones commonly used by employees of multinational companies. Participation in the project is free, the students have access to the Internet, the instructor is facilitating this interaction,rather than transferring her/his own knowledge, which is a major factor of educational management leading to successful learning. Another factor of such educational management is that instructional design focuses on the learners as the meaning makers and address the broad array of emotional and social opportunities and obstacles, that are likely to prompt effective learning. For example, real business entities serve as customers for the final product, so they set up the expected value as a final result of each project. According to the three stage change management concept (Kurt Levin) this setting secures unusual educational concept which allows participants to get aware of all the potential challenges of business and get ready to elaborate the inquiry for business skills.

The teams typically include students from different countries and they develop a business plan for a multinational company of the team's choice. The team reports must provide recommendations and a rationale for the location of the business, target market and market entry mode, staffing policies, financing options, product/service marketing, and other strategic decisions (Taras, Caprar, Rottig, et al. 2013.).

$\mathrm{X}$ culture project, like other global virtual team- based projects not only offers an opportunity for experiential learning, but also facilitates cross cultural management course learning improvement. As such,the project initiates the learning cycle by providing students with an opportunity to gain valuable, firsthand cross-cultural experience through guided reflection in the classroom, based on their experience and knowledge content of the academic course. As they are exposed into the international environment, they have to act accordingly, making decisions within international teams.

As Kolb holds it (1984), the learning cycle includes experiencing, reflecting, thinking, and acting. Experiencing constitutes the foundation for the cycle. Global virtual collaboration provides an excellent opportunity for all stages of the cycle, but is particularly important from the perspective of experiencing and acting - the two elements of the learning cycle that are often missing in the classroom. Coupled with instructor-facilitated activities that encourage reflecting on the experiences and thinking of better ways of completing the tasks, x culture project facilitates the complete learning cycle- experiencing, reflecting, thinking and acting - with a focus on aspects related to cross- cultural learning and competence development (Taras, Caprar, Rottig, et al. 2013.).

As we mentioned before, project participants develop a business proposal for a company of the team's choice. Although the expectations and the requirements of the final report are described in the manual, and a number of deadlines have to be met, the teams have autonomy with respect to their choice of communication mode and frequency, team coordination and leadership, workload distribution, and other aspects of teamwork.

Some features of the task may vary each semester, but the major task is to develop an idea for a new economically viable product for the client company and offer an analysis for its 
market entry. A real company is chosen as a "client," although the company is usually not directly involved in the project. Nevertheless, a number of companies partner with X-Culture and present real-life business cases at webinars they hold for students' teams to address various aspects in their business proposal.

We believe that working in a global team represents experiential and exploratory learning in one as it provides the ground for the entrepreneurial experience, embracing both success and failure, as an additional source of competence development. According to Shepherd (Shepherd at al., 2016), studying failures is more relevant to entrepreneurial education then success stories. We resonate with this statement and believe that learning in general should embrace the experience of failure in both group work and individual activity. As we observe, such kind of experience creates a basis for reflection, emotional pivot and evolution of risk appreciation

The X-Culture Project has become a required part of cross cultural management course for students in the institute of economics, management and tourism, and the project accounts for $20-35 \%$ of students' course grade. As we have been participating in the project since 2013, this resulted in around 100 students who completed the project.

The data sources we include here to analyze and discuss the results of such work include student surveys, peer evaluations, team report quality assessments by instructors and by students from other teams.

\section{Results and Discussion}

The design of the surveys to evaluate students' experience in $\mathrm{x}$ culture was aligned with our research questions, which we divided into three key assessment measures:

1.The first measure emerges from Experiential Learning theory based on the importance of involving and creating personal experience of students, which enables them to selftransform, thus succeeding in creating their life strategy.

2.The second measure emerges from the diverse body of intercultural theory and builds on the definition of intercultural competences as facilitating cultural sensitivity to and consideration for others.

3. The third measure emerges from the technology and pedagogy, and it is how to asses learning. We presume that experience improves understanding of the challenges and creates a basis for developing successful practices of global virtual collaboration.

A number of surveys were performed to evaluate students' reactions to the X-Culture Project. Around 65 students provided the feedback, 42 of which described the project as a positive experience. They believe that the experience they gained at the project will help them become effective managers in a cross cultural environment. Their comments usually included such evaluations of the project as "great experience," " practical exercise", they perceived learning as "successful journey into real business life" with specific references to improved teamwork skills -"I have learned a lot especially working with people I have never met" and cross-cultural skills - "I know I am now better prepared to work with people from other countries". In contrast, only 12 of the respondents evaluated the international collaboration exercise as a very "tough course", mainly as a result of challenges specific to their teams. Some found the project "frustrating" and "time-consuming," particularly in terms of managing team collaboration. Some challenges arise from cultural, language, time zone, and work style differences among the team members. However, most students appreciated these challenges as brilliant learning opportunities and were willing to participate in the same project again, because it is "a valuable experience", which facilitates self-transforming of students and thus, helps them build their own identities.

Another question we included in the survey aimed to test the effects of the online global project on students' perceptions of the course of cross cultural management quality and 
utility. Students speak strongly in favor of the experiential-learning project. When X-Culture became a part of the course, the student evaluations of the academic course became significantly more positive in spite of the fact that the X-Culture Project adds significant complexity to the structure of the course.

Overall, we found that globally distributed team work can influence people to approach cross-cultural exchanges with greater sensitivity, understanding, and ethical awareness in order to bring about improved international relations. Analyses of quantitative and qualitative data collected during evaluation (comprised of surveys, interviews, and observers' notes) shows that collaboration mediated by technology benefits students by preparing them to become successful Global Graduates of the $21^{\text {st }}$ century.

More specifically, we found that online global collaboration can provide us with means for overcoming our internal barriers to speak a foreign language in a new environment, overcoming stereotypes and misunderstandings in communication across cultural barriers, and overcoming intercultural communicative gaps. Stronger curricular methods can expand sensibility of students as they encounter other voices and experiences, and can improve their ability to collaborate, to listen to, and learn from each other.

An exit letter from one student taken from our sample of qualitative data, demonstrates the way in which our curriculum made possible student competences in communication, or a move from awareness to understanding: "I've made a long way to effective communication with people from different backgrounds. At first, people on the other side of the screen seemed like people from another planet to me. It's only after a long time of practice, thinking, reflections, when I began to understand cultural differences and the worldview of other people. Thanks to $\mathrm{x}$ culture that now I am a far more understanding and a far more successful in intercultural communication person. $X$ culture has provided an insight into other cultures and helped me understand ideas and thoughts of people from different backgrounds much better". The quantitative data gathered from exit surveys supports this testimony. In data combining 8 years of project implementation, $96 \%$ of students agree (some agree strongly) that they learned intercultural competences through the measure "developing cultural sensitivity to and consideration for others from diverse cultural contexts". Moreover, $90 \%$ of students agree with our first measure for self-transformation and constructing personal values, namely, they gained more self-understanding and thus are better equipped to consciously build their life strategy. 98\% percent of students agree (many strongly agree) that they "developed a better understanding of people from different cultural contexts".

What became an eye opening discovery is that most of the students changed their perception of cross-cultural differences after they completed the project. They found out that students from all over the world have more common features than differences, which is very promising with regard of how defensive vs. inclusive brain works, according the neuroscience studies. International experience may activate students' inclusive brain work to accept cultural differences as opportunities to learn from each other rather than escape and/or defend their own cultural values. Anyway, it helps them to get better prepared for a career in global business.

These strong positive findings suggest that the project curriculum, research methodology, and online pedagogy are working to address the educational challenge outlined in this paper.

In assessing learning, we also examined the utility of assignments designed to facilitate in-depth and self-directed learning, and we studied the implementation of technology designed to facilitate intercultural competences in cross-cultural collaboration. Through a comparison of different assignments (asking students to rate the value of each one for their learning), we learned that students achieved deep learning from collaborative activities, and from exchange of ideas on business cases/ situations/problems in their countries and in the world. The qualitative data supported this exit survey results, as one student stated:" $\mathrm{x}$ culture 
provides us a chance to meet people and to discuss diverse topics of our mutual interest with them as well as to try and find solutions to various problems in economic situations".

In addition, the data indicated that students learned a lot of useful skills over the project. For example, they learned how to search for additional information on the Internet while preparing for discussions on specific topics. As one of the student, who graduated 5 years ago remarked: "What I learned from these activities was a set of different useful skills: how to communicate with people in general and with people representing other cultures, in particular; how to present my ideas; how to work in a team, to share responsibility and act together; also, I have raised my level of written and spoken English and made many international contacts. All these skills have helped me a lot in my life. To start with, I can fruitfully communicate with people from other cultures. However, simple it sounds; it is far more sophisticated than it seemed at first sight. Not taking language into account, it's just great to realize how different yet alike people on earth are, and how conscious one must be to effectively communicate with them. I broke some of my earlier stereotypes, which now makes me think of what I really know about other cultures. I learned not to apply the rules of my culture to everyone else in the world".

In summary, the data from these evaluation measures (both the statistical data from our exit surveys and reflections on students' participating in our classes) suggest to us the merit of the online global learning in succeeding further in life.

We argue that the main outcome of online global education, like $\mathrm{x}$ culture project, is the student's "awakened" ability to self-develop and to construct/fulfil her/his own life strategy according to her/his personal hierarchy of meanings and values. This outcome is hardly assessable in a traditional way as it is pervasive and it makes a difference in a personality. According to A. Nagata, "It involves experiencing a deep, structural shift in the basic premises of thought, feelings, and actions. It is a shift of consciousness that dramatically and permanently alters our way of being in the world" (Nagata, 2007, p.16). Harvard psychologist Ellen Langer uses the term mindfulness to describe "the continuous creation of implicit selfawareness of more than one perspective in life" (Langer, 2000, p.19).

By observation, the students who engaged in x culture activities, acquired skills of coconstructing personal knowledge when interacting with their peers in regular academic classes, which is novel in contrast with former "knowledge gathering" from teachers and books. For example, they are more actively involved in dialogues and reflections in academic classes, and they perceive things more critically. They obviously became more open and less rigid in expressing themselves in and outside classrooms. Their attitude toward school changed immensely since they discovered that they can use their own experience and feel personal engagement in studies.

Reaching out contributed a lot to overcome egocentrism of ideas as expressed in students' essays: " $x$ culture activities embedded in cross cultural management course help us understand what we are and how we relate to each other as individuals from different cultures, this motivates me to learn more about myself as a human being ", "I realized that x culture reveals much of what we have in common with other cultures as well as how different we are, and this makes me appreciate the diversity in the world".

We concluded from students' academic and social performances and from student completed questionnaires, that in the process of learning within $\mathrm{x}$ culture project, they acquired self-management skills, became more efficient in planning and setting goals, and raised their degree of satisfaction with self-realization. Interviews with students revealed that global learning activities enriched their personal meanings and transformed their hierarchies of values. The students increasingly recognized the value of a unique individual and his/her freedom to consciously construct her/his life strategy on the basis of universal moral values. The locus of self-control indicates that they are getting more and more control over their lives as they engage in meaningful global learning activities. We regard these indicators as subtle 
but promising indicators of students' activated capabilities to taking more responsibilities for the authenticities of their lives. According to the related literature on philosophy and psychology of a human being's development, this can/will facilitate their efforts to grow personally and professionally, if their education supports it. As educators, we consider it our major task - to provide conditions and opportunities for an individual to become an author of her/his life.

\section{Conclusion}

The globalizing workplace environment increases the need for cross-cultural and virtual collaboration skills across all organizational levels, professions, and industries. Our paper advances understanding that online experiential learning in general and $\mathrm{x}$ culture project in particular, provide conditions and opportunities for students to develop these skills, and thus to succeed in life

The context of the project allows students to work as if they work in real corporate global virtual teams. They apply the same communication tools and solve real life cases. The instructors serve as supervisors, assign the tasks and facilitate their performance. The companies and instructors evaluate the final products students create.

The evidence suggests that the international collaboration project leads to changes in behaviors and attitudes of participants, particularly with respect to responsibility, team leadership, communication, which indicates transformation of their life values and thus provides evidence that the project has the potential to improve the participants' future performance.

Our findings also illustrate the value of supportive management in higher education, opposed to hierarchical and instrumental one. Supportive management in education becomes a key factor in successful learning for students. Theoretical perspectives in evaluating and explaining the effectiveness of a supportive teaching approach turn highly valuable. The theory of transformative, meaning -centered and experiential education we apply in our research, suggest that $\mathrm{x}$ culture provides these types of learning in full scope.

The experience students gain over the course of the project lead to a shift in their attitudes and behaviors. As a result, their performance improve in other academic studies, their involvement increase substantially, and students do much better further in life, which indicates the potential of their success at a later time.

As online education matures, increasing energy in education management must shift from provision technology to ensuring each learner's success. We hold that online education presents new opportunities not just in the mechanics of higher education, but for improving students' experience and outcomes. Central to such improvement is a clear picture of study success, supportive management in education and more evidence-based academic leadership.

\section{References}

1. I. Alon, J. of Teaching in International Business, 14, 79 (2003)

2. L. Baartman, L. Ruijs (2011), Assessment \& Evaluation in Higher Education, 36(4), 385 (2011)

3. H. Beetham, R. Sharpe, Rethinking Pedagogy for Digital Age; Designing for $21^{\text {st }}$ Century Learning (2013)

4. S. Brookfiled, The Critically Reflective Teacher. San Fransisco (1995)

5. R. S. Cheney, Business Communication Quarterly, 64, 90 (2001) 
6. H. Coates, Student Engagement in Campus-Based and Online Education: University Connections (2006)

7. P. Cranton, Understanding and Promoting Transformative Learning (1994)

8. J. Dewey, Experience and Education (1938)

9. D. A. Kolb, Experiential learning. Englewood Cliffs (1984)

10. O. Kovbasyuk, P. Blessinger, Meaning -Centered Education: International Perspectives and Explorations in Higher Education (2013)

11. P. Kelly, H. Coates, R. Naylor, Education Issues, 3, 34 (2016)

12. J. Merizow, Transformative Dimensions of Adult Learning (1991)

13. J. Mezirow, E. W. Taylor, Transformative Learning in Practice: Insights from Community, Workplace and Higher Education (2009)

14. D. Laurillard, Rethinking University Teaching; A Conversational Framework for the Effective Use of Learning Technologies (2013)

15. D. Leontiev, Emerging Contexts and Meanings of Human Education in Meaning Centered Education: International Perspectives and Explorations in Higher Education (2013)

16. P. Paul, K. Mukhopadhyay, J. of Teaching in International Business, 16, 7 (2005)

17. V. Savicki, Developing Intercultural Competence and Transformation (2008)

18. D. Shepherd, T. Williams, M. Wolfe, , H. Patzelt, Learning from Entrepreneurial Failure: Emotions, Cognitions, and Actions (2016)

19. Taras, Caprar, Rottig, et al., Academy of Management Learning \& Education, 12(3), 414 (2013)

20. N. Zepke, L. Leach, Teaching in Higher Education, 15(6), 661 (2010) 